Кузнецова Мария Олеговна аспирант, ФГОБУ ВО «Финансовый университет при Правительстве Российской Федерации», г. Москва, Российская Федерация

e-mail: m-kuzn2011@yandex.ru

\section{Kuznetsova Maria}

Postgraduate student, Financial University under the Government of the Russian Federation, Moscow, Russia

e-mail: m-kuzn2011@yandex.ru

\section{УПРАВЛЕНИЕ РИСКАМИ УСТОЙЧИВОСТИ ПРОМЫШЛЕННЫХ ОРГАНИЗАЦИЙ}

Аннотация. Рассмотрены особенности управления рисками устойчивости промышленных организачий. Выявлены тенденции снижения устойчивости промышленных организаичй России. Обоснованы этапы управления факторами риска устойчивости организаций. Выделены однородные группы промышленных организаций, имеющих близкое по своим характеристикам состояние, что повышает эффективность анализа рисков. Проведен качественный анализ факторов риска на основе источников сети «Интернет» и оченка показателей финансово-экономического состояния промышленных организаций; сформирован массив внешних и внутренних факторов риска, влияющих на устойчивость промышленных организачий.

Ключевые слова: устойчивость промышленных организаций, кризис, система рискменеджмента, факторы риска, анализ рисков, банкротство организаций.

Цитирование: Кузнецова М.О. Управление рисками устойчивости промышленных организаций//Вестник университета. 2019. № 6. С. 105-114.

\section{THE RISK MANAGEMENT OF SUSTAINABILITY OF INDUSTRIAL ORGANIZATIONS}

\begin{abstract}
The features of risk management of stability of the industrial organizations have been considered. The trends of loss of sustainability have been revealed by the industrial organizations of Russia. Stages of risk management of stability of the organizations have been substantiated. Homogeneous groups of industrial organizations with similar characteristics state have been identified, which increases the efficiency of the risk analysis. The qualitative analysis of risk factors on the basis of the Internet sources and assessment of financial and economic indicators of industrial organizations has been carried out; an array of external and internal factors of risk, affecting sustainability of the industrial organizations, has been created.
\end{abstract}

Keywords: sustainability of industrial organizations, crisis, risk management system, risk factors, risk analysis, bankruptcy of organizations.

For citation: Kuznetsova M.O. The risk management of sustainability of industrial organizations (2019) Vestnik universiteta, I. 6, pp. 105-114. doi: 10.26425/1816-4277-2019-6-105-114

Промышленные организации функционируют в постоянно меняющихся условиях под воздействием внешних и внутренних факторов риска, которые оказывают влияние на их устойчивость. Под устойчивостью промышленной организации понимается ее способность сохранять свои признаки под воздействием изменений, вызванных различными факторами [3]. Следовательно, чтобы управлять устойчивостью, необходимо управлять факторами риска.

Потеря устойчивости может привести к кризису промышленной организации. Если рассматривать кризис на различных стадиях, таких как преддверие кризиса, кризис и разрушение (ликвидация) системы, то банкротство (ликвидация) организации является последней стадией потери устойчивости [2].

Важно управлять рисками на каждом этапе кризиса, когда можно своевременно принять меры по их предотвращению или снижению уровня их воздействия, т. е. при управлении устойчивостью большое значение имеет комплексный подход в риск-менеджменте.

В Российской Федерации (далее - РФ) в настоящее время наблюдается снижение устойчивости промышленных организаций. Данный факт подтверждается отрицательной динамикой количества процедур банкротства в России. В таблице 1 представлена динамика количества процедур банкротства в России за 2014-2018 гг. [8; 10].

(C) Кузнецова М.О., 2019. Статья доступна по лицензии Creative Commons «Attribution» («Атрибуция») 4.0. всемирная (http://creativecommons.org/licenses/by/4.0/).

The Author(s), 2019. This is an open access article under the CC BY 4.0 license (http://creativecommons.org/licenses/by/4.0/).

(c) (i) 
Количество дел о несостоятельности (банкротстве) в РФ за 2014-2018 гг.

\begin{tabular}{|c|c|c|c|c|c|c|c|}
\hline \multirow{2}{*}{$\begin{array}{c}\text { Данные по делам о несосто- } \\
\text { ятельности (банкротстве) } \\
\text { в РФ }\end{array}$} & \multicolumn{5}{|c|}{ Год } & \multirow{2}{*}{$\begin{array}{l}\text { Абсолютное изме- } \\
\text { нение показателей } \\
\text { за 2014-2018 гг. }\end{array}$} & \multirow{2}{*}{$\begin{array}{c}\text { Относительное } \\
\text { изменение пока- } \\
\text { зателей за 2014- } \\
2018 \text { гг., \% }\end{array}$} \\
\hline & 2014 & 2015 & 2016 & 2017 & 2018 & & \\
\hline $\begin{array}{l}\text { Поступило заявлений о призна- } \\
\text { нии должника банкротом }\end{array}$ & 41996 & 50779 & 67744 & 38951 & 36726 & -5270 & 87 \\
\hline $\begin{array}{l}\text { Количество дел, по которым в от- } \\
\text { четном периоде введены реаби- } \\
\text { литационные процедуры (фи- } \\
\text { нансовое оздоровление, внешнее } \\
\text { управление и мировое соглашение) }\end{array}$ & 882 & 958 & 957 & 882 & 848 & -34 & 96 \\
\hline $\begin{array}{l}\text { Количество дел, по которым в от- } \\
\text { четном периоде введены ликви- } \\
\text { дационные процедуры (конкурс- } \\
\text { ное производство) }\end{array}$ & 15096 & 14916 & 14127 & 14142 & 13254 & -1842 & 88 \\
\hline
\end{tabular}

Источник: [8; 10].

Согласно данным таблицы 1 в 2018 г. количество ликвидационных процедур - процедуры конкурсного производства (13 254) - значительно превышает количество реабилитационных процедур - процедуры финансового оздоровления, внешнего управления и мирового соглашения (848). Это свидетельствует о том, что большинство организаций достигли последней стадии потери устойчивости - ликвидации (банкротства). Динамика изменения количества процедур банкротства представлена на рисунке 1.

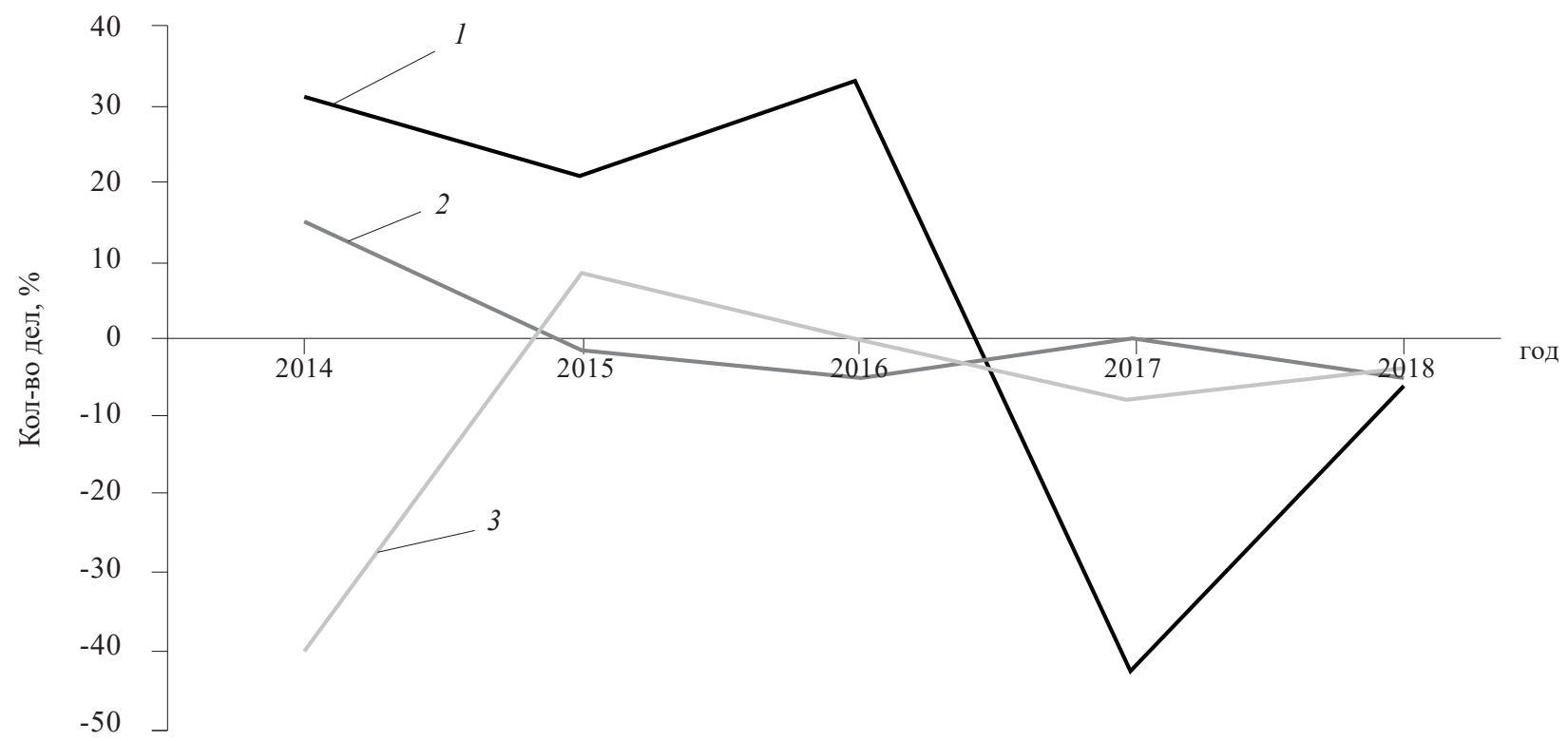

1 - поступило заявлений о признании должника банкротом; 2 - кол-во дел, по которым в отчетном периоде введены ликвидационные процедуры (конкурсное производство); 3 - кол-во дел, по которым в отчетном периоде введены реабилитационные процедуры (финансовое оздоровление, внешнее управление и мировое соглашение)

Источник: [7;8]

Рис. 1. Динамика количества дел о несостоятельности (банкротстве) в РФ за 2014-2018 гг. 
В 2017-2018 гг. наблюдалось снижение количества поступивших заявлений о банкротстве. Однако в 2018 г. темп снижения количества реабилитационных процедур стал замедляться. Следовательно, данные организации являлись неустойчивыми, они не смогли противостоять влиянию факторов риска, что и привело к их банкротству. Кроме того, для большинства организаций, находящихся в процедурах банкротства, восстановление платежеспособности оказалось невозможным, что привело к их ликвидации, т. е. они прекратили свое существование в данном виде. Стоит отметить, что в 2018 г. наблюдалось снижение количества ликвидационных процедур. Однако, их общее количество значительно превышает количество реабилитационных процедур.

Таким образом, на формирование кризиса и потерю устойчивости влияют различные факторы риска. Следовательно, обеспечение устойчивости должно основываться на системе управления факторами риска, что позволит предотвратить потерю устойчивости и сохранить организацию.

Для обеспечения устойчивости промышленных организаций важно применение элементов антикризисного управления. Возможны три сценария развития кризиса: сохранение системы с ее обновлением и возврат ее в стабильное состояние; разрушение системы и невозможность ее дальнейшего функционирования; консервация кризиса, что может привести к возникновению кризиса вновь.

Выделяют 4 вида антикризисного управления (рис. 2).

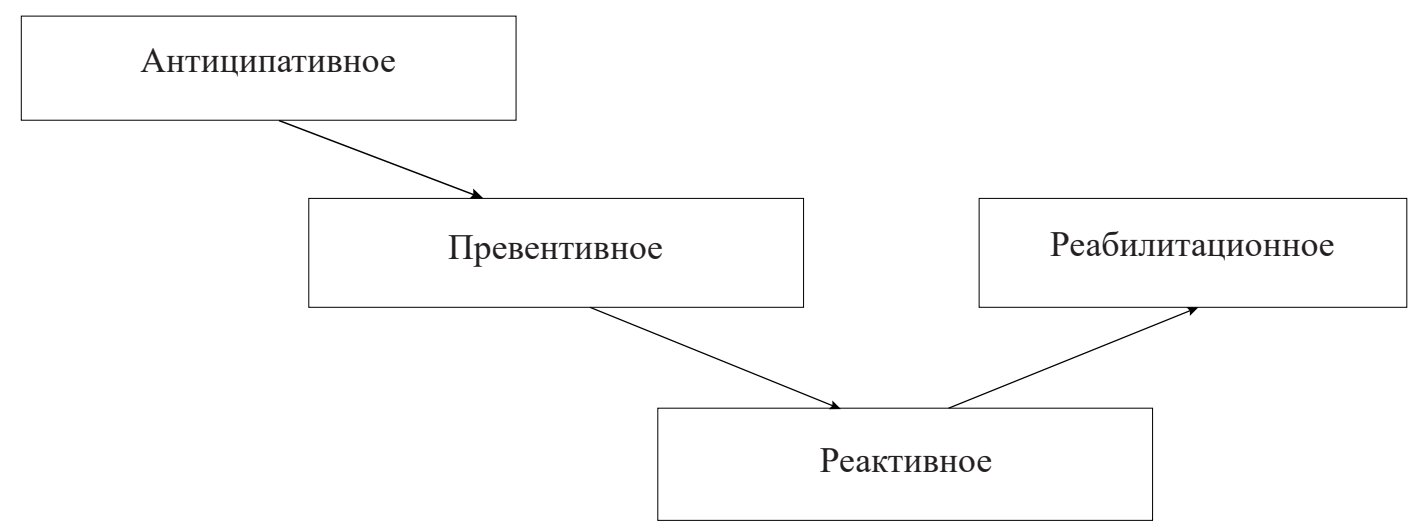

Источник: [2, с. 10]

Время

Рис. 2. Виды антикризисного управления

Антиципативное управление требует заблаговременную проработку возможных внешних и внутренних факторов, которые могут привести промышленную организацию к возникновению кризиса. Антиципативное управление проводится задолго до возникновения каких-либо факторов, которые могут оказывать воздействие на устойчивость промышленной организации. Антиципативное управление обеспечивает готовность бизнеса к возникновению негативных воздействий и своевременного реагирования на них.

Превентивное управление проводят после того, как обнаружат признаки возникновения кризиса, которые могут развиваться, если не будет предпринято никаких мер по их блокированию. В период превентивного управления достигается снижение негативных факторов, что помогает снизить проявление негативных последствий кризиса.

Реактивное антикризисное управление проводится после наступления кризиса. В данном случае применяются специфические антикризисные инструменты, такие как санация и реструктуризация. Активно используются внешние и внутренние ресурсы промышленной организации для выхода из кризиса.

Реабилитационное антикризисное управление предполагает усиление сопротивляемости промышленной организации после преодоления кризиса, восстановление устойчивости организации.

Таким образом, все виды управления должны быть встроены в единую систему управления организацией. Выстроенный процесс антикризисного управления позволит обеспечить устойчивое развитие промышленной организации и поможет избежать банкротства [2]. Риск-менеджмент позволяет оценивать и управлять 
различными факторами риска, которые оказывают влияние на возникновение кризиса и потерю устойчивости промышленных организаций. Следовательно, риск-менеджмент является составляющей антикризисного управления и осуществляется на разных уровнях управления.

Комплексный подход в риск-менеджменте предполагает выявление факторов риска на различных стадиях их проявления. В настоящий момент используется алгоритм по управлению рисками, предложенный в системе COSO, который описывает взаимосвязь между целями организации и необходимыми компонентами процесса управления рисками; дает характеристику этапам риск-менеджмента. Однако, в данном стандарте не рассматриваются конкретные методы оценки и управления рисками, т. е. нет четкого описания, какими методами и подходами к оценке и управлению должны руководствоваться промышленные организации. Предлагается методика управления устойчивостью промышленных организаций, которая позволит анализировать риски на различных стадиях кризиса, что поможет избежать банкротства промышленных организаций и сохранить их устойчивость.

Данная методика будет основываться на подходе COSO, который используется для управления рисками [4; 11$]$.

Таким образом, подход по управлению устойчивостью промышленных организаций состоит из семи этапов (рис. 3).

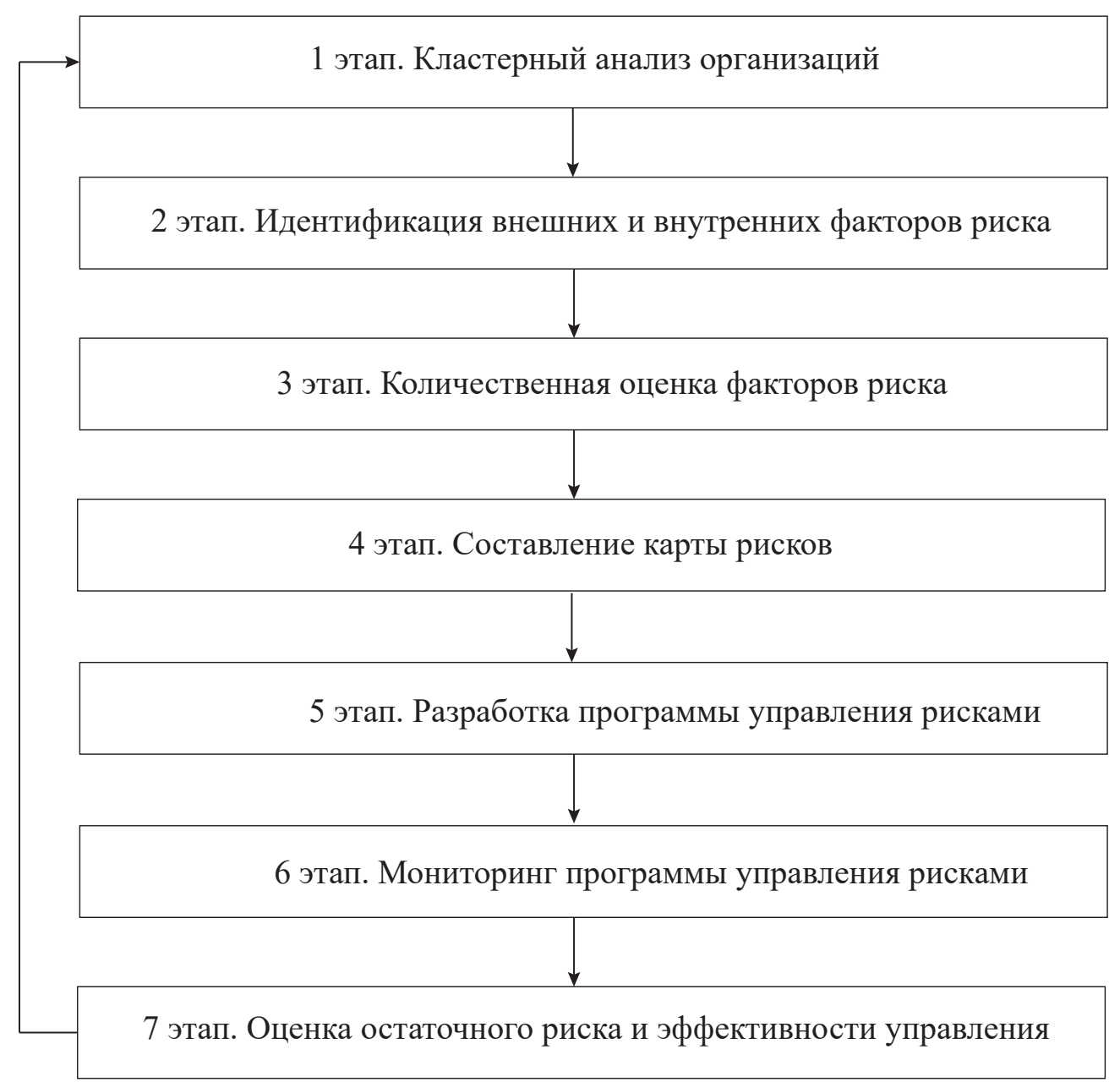

Составлено автором по материалам [11]

Рис. 3. Подход по управлению устойчивостью промышленных организаций

Рассмотрим цели и задачи каждого этапа.

1. Кластерный анализ организаций. Проводится с целью выявления однородных групп, имеющих близкие характеристики состояния, что позволит оценивать присущие той или иной однородной группе риски и управлять ими; разрабатывать методы оценки и управления для конкретной группы. Следовательно, это обеспечит более обоснованные результаты и повысит эффективность управления устойчивостью промышленных организаций. 
2. Идентификация внешних и внутренних факторов риска. Направлена на выявление всех возможных рисков, влияющих на устойчивость промышленных организаций. Данный этап позволит сформировать весь массив факторов риска, влияющих на устойчивость организаций.

3. Количественная оценка факторов риска. Проводится с целью определения значимости факторов риска: по степени влияния на устойчивость организации и по вероятности возникновения. Данный этап позволяет проранжировать факторы риска по уровню их значимости и существенности воздействия на устойчивость организаций.

4. Составление карты рисков. Позволяет определить наиболее существенные риски, оказывающие воздействие на устойчивость промышленных организаций. Основная цель составления карты рисков - выявление катастрофических факторов риска, оказывающих наибольшее воздействие на устойчивость организаций. Для этих рисков в дальнейшем будет разрабатываться программа по управлению рисками.

5. Разработка программы управления рисками. Позволит выработать систему мероприятий по управлению катастрофическими факторами риска, выявленными на предыдущем этапе. По каждому фактору риска должны быть предложены мероприятия по управлению с указанием сроков и ответственных отделов (департаментов) промышленных организаций.

6. Мониторинг программы управления рисками. Формируется система мониторинга для непрерывного управления факторами устойчивости. Благодаря данному этапу, станет возможным выявлять факторы риска на различных стадиях их проявления. Разрабатывается система показателей, с помощью которых можно оценить изменения факторов риска и устойчивости организации.

7. Оценка остаточного риска и эффективности управления. Позволит осуществлять корректировку системы управления рисками по мере необходимости. Данный этап предполагает сравнение значений показателей до и после осуществления программы управления рисками с возможностью корректировки системы управления рисками, т. е. позволяет вернуться к первому этапу управления рисками.

Предложенный алгоритм управления рисками устойчивости промышленных организаций позволит:

- выделить однородные группы организаций, имеющие близкие характеристики и условия. Каждая организация имеет свои индивидуальные особенности. Это означает, что система управления рисками должна разрабатываться для каждой компании. Кластеризация организаций позволяет выделить однородные группы компаний, для которых становится возможным разработать универсальную систему управления рисками для обеспечения устойчивости, которую можно впоследствии адаптировать под каждую организацию;

- выявить и оценить наиболее значимые риски, влияющие на устойчивость промышленной организации на различных стадиях кризиса, что позволит сформировать соответствующую систему мероприятий для управления устойчивостью организации;

- разработать программу управления рисками, которая позволит использовать комплексный подход к управлению устойчивостью промышленных организаций и не перейти в более острую фазу кризиса;

- проводить непрерывный мониторинг факторов риска, что дает возможность выявлять факторы риска на разных стадиях кризиса и не допустить их обострения для организации;

- оценивать эффективность существующей системы управления устойчивостью промышленной организации с учетом факторов риска, что позволяет осуществлять непрерывную корректировку системы.

Основное внимание в статье уделено первым двум этапам:

- кластерный анализ промышленных организаций;

- идентификация внешних и внутренних факторов риска устойчивости организаций.

Они являются наиболее важными, т. к. позволяют:

- выявлять однородные группы организаций со схожими характеристиками. Следовательно, повышать эффективность дальнейшей оценки факторов риска;

- формировать перечень всех факторов, оказывающих влияние на устойчивость промышленных организаций той или иной группы.

Эти этапы позволят выявлять факторы риска на разных стадиях кризиса, что поможет своевременно разработать программу управления факторами риска и не даст организации перейти в более острую фазу кризиса и, соответственно, потерять устойчивость. От качества проведенного анализа факторов устойчивости зависит эффективность всей системы управления рисками. 
В статье представлена методика проведения соответствующих этапов рисков устойчивости промышленных организаций. На первом этапе проводился кластерный анализ, в результате была выделена однородная группа промышленных организаций, имеющих близкое по своим характеристикам состояние.

Для проведения кластерного анализа промышленных организаций были использованы данные по 197 действующим организациям России по коду ОКВЭД 28.91 «Производство машин и оборудования для металлургии» [1]. Информация об организациях получена из системы СПАРК [9]. Кластерный анализ проведен с помощью программного пакета Statistica.

В качестве переменных, по которым проводилась кластеризация промышленных организаций, были выбраны следующие показатели: активы, выручка, среднесписочная численность персонала организаций. Выбор показателей, по которым проводилась кластеризация промышленных организаций не случайна:

Активы представляют собой имущественный комплекс организации, т. е. все, чем владеет организация. Наличие активов дает возможности для развития организации. Данный показатель позволяет выделить однородные группы промышленных организаций по масштабу деятельности.

Показатель выручки отражает объем продаж и, следовательно, уровень спроса на продукцию промышленной организации; позицию на соответствующем сегменте рынка.

Показатель среднесписочной численности промышленной организации показывает наличие трудовых ресурсов организации и кадровый потенциал.

В результате проведенного кластерного анализа, все компании были разделены на 3 кластера. В таблице 2 представлены результаты кластерного анализа и основные характеристики соответствующих групп (кластеров).

Таблица 2

Результаты кластерного анализа промышленных организаций машиностроения для металлургии

\begin{tabular}{|c|c|c|c|c|}
\hline Показатель & Кластер 1 & Кластер 2 & Кластер 3 & Сумма \\
\hline Количество организаций & 3 & 4 & 190 & 197 \\
\hline Активы, руб. & 0 & 13817212000 & 10242740000 & 24059952000 \\
\hline Среднее значение активов, руб. & 0 & 3454303000 & 53909157,89 & - \\
\hline Доля активов в общей сумме, \% & 0 & 57 & 43 & - \\
\hline Выручка, руб. & 0 & 11915263000 & 12299638000 & 24214901000 \\
\hline Среднее значение выручки, руб. & 0 & 2978815750 & 64734936,84 & - \\
\hline Доля выручки в общей сумме, \% & 0 & 49 & 51 & - \\
\hline $\begin{array}{l}\text { Среднесписочная численность пер- } \\
\text { сонала, чел. }\end{array}$ & 15000 & 11403 & 5863 & 32266 \\
\hline $\begin{array}{l}\text { Среднее значение среднесписочной } \\
\text { численности персонала, чел. }\end{array}$ & 5000 & 2851 & 31 & - \\
\hline $\begin{array}{l}\text { Доля среднесписочной численности } \\
\text { персонала, \% }\end{array}$ & 46 & 35 & 19 & - \\
\hline
\end{tabular}

Источник: [9]

На основе кластерного анализа были выделены три группы промышленных организаций по трем признакам: активы, выручка и среднесписочная численность.

Для оценки эффективности кластерного анализа был проведен дисперсионный анализ. Полученные данные подтверждают, что классификация промышленных организаций на три кластера обоснована следующими критериями:

- неравенство значений F-критерия $(154,3 ; 296,1$ и 468,1 по показателям активы, выручка и среднесписочная численность соответственно). Гипотеза о неравенстве дисперсий между кластерами и внутри них верна. Это означает, что данные являются статистически неоднородными и могут быть разделены на группы; 
- значения уровней значимости $(\mathrm{p}<0,05)$ свидетельствуют о низкой вероятности недостоверности полученных результатов. Следовательно, разделение промышленных организаций на три группы обосновано;

- внутригрупповые дисперсии $(75,7 ; 48,4$ и 33,6) по переменным «активы», «выручка» и «среднесписочная» численность меньше, чем межгрупповые значения дисперсий $(120,3 ; 147,6$ и 162,4) соответственно. Следовательно, выбранные переменные качественно характеризуют принадлежность организаций к тому или иному кластеру $[5 ; 6 ; 9]$.

Кластер 1 характеризуется высокой среднесписочной численностью персонала 5000 чел., что составляет $46 \%$ от всего персонала отрасли. Три организации первого кластера работают в области инжиниринга и фактически не относятся к машиностроительным организациям. Следовательно, проводить дальнейшую оценку факторов риска и разработку программы по управлению рисками следует для другого кластера.

Кластер 2 включает в себя 4 организации. Согласно данным системы СПАРК, организации кластера 2 относятся к категории крупных предприятий [9]. Доля активов и выручки организаций, входящих в кластер 2, составляет около половины всех активов и выручки отрасли. Если рассматривать средние значения показателей промышленных организаций кластера, то следует отметить, что данные организации обладают сравнительно высоким уровнем активов и выручки, что делает возможным внедрение системы комплексного управления рисками устойчивости.

В кластер 3 входит 190 организаций. К их числу относятся средние, малые и микро-организации. Доля активов и выручки организаций, входящих в кластер 3, составляет около 50 \% всех активов и выручки отрасли. Лишь 18 \% всего персонала отрасли работает в организациях третьего кластера.

Сравнивая второй и третий кластер промышленных организаций, следует отметить, что:

- доля активов в общей сумме кластера 2 составляет 57 \%, что превосходит соответствующий показатель кластера 3 - $43 \%$;

- доля среднесписочной численности кластера 2 (35\%) значительно превосходит соответствующий показатель кластера 3 (19 \%);

- по доле выручки кластер 2 (49 \%) незначительно уступает кластеру 3 (51 \%). Возможно, это связано с неэффективной хозяйственной деятельностью организаций второго кластера.

Таким образом, второй кластер промышленных организаций является основой отрасли, т. к. превосходит по показателям активов и среднесписочной численности персонала третий кластер промышленных организаций. Дальнейшие мероприятия по оценке и управлению рисками будут разрабатываться для организаций второго кластера.

На втором этапе была проведена идентификация внешних и внутренних факторов риска.

По второму кластеру был проведен качественный анализ рисков, который позволил выявить факторы, оказывающие воздействие на устойчивость данной группы организаций.

Качественный анализ факторов проводился на основе сравнения и сопоставления данных открытых источников сети «Интернет» (Федеральной службы государственной статистики, Глобального инновационного индекса (GII), системы СПАРК) и динамики показателей финансово-экономического состояния промышленных организаций. По итогам качественного анализа была составлена система факторов риска и предложена ее классификация. Результаты качественного анализа представлены в таблице 3.

Таблииа 3

Факторы риска промышленных организаций второго кластера

\begin{tabular}{|l|l|}
\hline \multicolumn{1}{|c|}{ Группа факторов } & \multicolumn{1}{|c|}{\begin{tabular}{c}
\multicolumn{1}{|c|}{ Фактор риска } \\
\hline Экономические риски
\end{tabular}} \\
\hline \multicolumn{1}{|c|}{\begin{tabular}{l}
\multicolumn{1}{|c|}{ Внешние риски } \\
Повесочение экономических санкций \\
Повышение уровня налогообложения \\
Недостаточный спрос на внутреннем рынке \\
Низкий экспорт продукции
\end{tabular}} \\
\hline
\end{tabular}


Окончание табл. 3

\begin{tabular}{|c|c|}
\hline Группа факторов & Фактор риска \\
\hline Научно-технические риски & $\begin{array}{l}\text { Уровень развития коммерциализации инновационной деятельности } \\
\text { Уровень интеграции цифровых технологий между хозяйствующими } \\
\text { субъектами } \\
\text { Уровень внедрения инновационных технологий }\end{array}$ \\
\hline Социальные риски & Дефицит научно-технических кадров \\
\hline & Внутренние риски \\
\hline Риски производственной деятельности & $\begin{array}{l}\text { Повышение темпов обновления основных средств и нематериальных } \\
\text { активов ускоренными темпами } \\
\text { Дефицит высокотехнологичного сырья и материалов }\end{array}$ \\
\hline Риски финансовой деятельности & $\begin{array}{l}\text { Ограниченность финансовых ресурсов для развития } \\
\text { Проблема платежеспособности } \\
\text { Сложность привлечения внешних источников финансирования за рубежом } \\
\text { Снижение рентабельности организации }\end{array}$ \\
\hline
\end{tabular}

Источник: [7; 9; 12]

Таким образом, по итогам качественного анализа рисков были выделены группы внешних и внутренних факторов риска. К внешним факторам риска отнесены экономические, научно-технические и социальные риски. К внутренним факторам риска - риски производственной и финансовой деятельности.

Группа экономических рисков характеризуется сложностью и неопределенностью экономической обстановки, угрозой ужесточения экономических санкций.

В условиях влияния процессов Индустрии 4.0 усиливается влияние научно-технических рисков для промышленных организаций: повышается роль уровня развития цифровой интеграции между хозяйствующими субъектами; внедрения инновационных технологий. Кроме того, возникает потребность в научно-технических кадрах, т. е. усиливается роль социальных рисков.

В условиях сложной экономической обстановки и процессов Индустрии 4.0 возникает необходимость в повышении темпов обновления основных средств и нематериальных активов, а также в использовании высокотехнологичного сырья для производства.

Для внедрения нового оборудования и привлечения персонала с высоким уровнем квалификации необходимы внешние и внутренние источники финансирования. Однако, существует сложность привлечения источников финансирования за рубежом ввиду экономических санкций. Также наблюдаются проблемы с платежеспособностью и низкой рентабельностью организаций.

Таким образом, качественный анализ факторов риска позволил:

- выделить перечень рисков, оказывающих воздействие на устойчивость промышленных организаций;

- систематизировать данные факторы, выделить группы рисков, оказывающих влияние на устойчивость.

Следующими этапами системы управления рисками являются: количественные анализ и оценка факторов риска; составление карты рисков; разработка программы управления рисками; формирование системы мониторинга факторов риска; оценка остаточного риска и эффективности управления.

В статье был предложен алгоритм управления рисками устойчивости промышленных организаций, состоящий из 7 этапов. Данный подход позволяет управлять устойчивостью организаций с помощью риск-менеджмента. Основное внимание уделено первым двум этапам, связанным с выявлением однородных групп промышленных организаций, что позволяет повысить качество разрабатываемой системы управления устойчивостью, и формированием массива факторов риска, воздействующих на устойчивость однородной группы организаций. Предложенный подход позволит осуществлять комплексное управление факторами риска устойчивости промышленных организаций. 
Библиографический список

1. ОК 029-2014 (КДЕС Ред. 2). Общероссийский классификатор видов экономической деятельности (утвержденный Приказом Росстандарта от 31.01.2014 г. № 14-ст) (ред. от 20.02.2019 г.) [Электронный ресурс]. - Режим доступа: Справочная правовая система «КонсультантПлюс» http://www.consultant.ru/cons (дата обращения: 28.04.2019).

2. Антикризисное управление как основа формирования механизма устойчивого развития бизнеса: монография / под ред. А. Н. Ряховской, С. Е. Кована. - М.: ИНФРА-М, 2019. - 169 с.

3. Кован, С. Е. Теория антикризисного управления социально-экономическими системами (ресурсный подход): монография / С. Е. Кован. - М.: НИЦ ИНФРА-М, 2016. - 160 с.

4. Крюкова, О. Г. и др. Риск-менеджмент - основа устойчивости бизнеса: учебное пособие / А. Н. Ряховская, О. Г. Крюкова, М. О. Кузнецова; под ред. О. Г. Крюковой. - М.: Магистр: ИНФРА-М, 2019. - 256 с.

5. Салин, В. Н. Статистический анализ данных цифровой экономики в системе «STATISTICA»: учебно-практическое пособие / В. Н. Салин, Э. Ю. Чурилова. - М.: КНОРУС, 2019. - 238 с.

6. Соловьев, В. И. Анализ данных в экономике: теория вероятностей, прикладная статистика, обработка и визуализация данных в Microsoft Excel: учебник / В. И. Соловьев. - М.: Кнорус, 2019. - 498 с.

7. Промышленное производство в России [Электронный ресурс]//Федеральная служба государственной статистики (Росстат). - Режим доступа: http://www.gks.ru/wps/wcm/connect/rosstat_main/rosstat/ru/statistics/publications/catalog/ doc_1139918730234 (дата обращения: 13.04.2019).

8. Рассмотрение дел о несостоятельности (банкротстве) [Электронный ресурс]//Федеральные арбитражные суды Российской Федерации. - Режим доступа: http://www.arbitr.ru/ (дата обращения: 14.04.2019).

9. Система СПАРК [Электронный ресурс]//Интерфакс. - Режим доступа: http://www.spark-interfax.ru/\#_top (дата обращения: 28.04.2019).

10. Судебный Департамент при Верховном суде Российской Федерации [Электронный ресурс] / Верховный суд Российской Федерации. - Режим доступа: http://www.cdep.ru/index.php?id=79 (дата обращения: 14.04.2019).

11. ERM-COSO Enterprise Risk Management - Integrated Framework Committee of Sponsoring Organizations of the Treadway Commission (COSO), USA [Электронный ресурс]//Committee of Sponsoring Organizations of the Treadway Commission (COSO). - Режим доступа: https://www.coso.org/Pages/default.aspx (дата обращения: 23.04.2019).

12. Global Innovation Index [Электронный ресурс]. - Режим доступа: https://www.globalinnovationindex.org/home (дата обращения: 29.04.2019).

\section{References}

1. OK 029-2014 (KDES Red. 2) Obshcherossiiskii klassifikator vidov ekonomicheskoi deyatel'nosti (utverzhdennyi Prikazom Rosstandarta ot 31.01.2014 g. № 14-st) (red. ot 20.02.2019 g.) [OK 029-2014 (KDES of the Edition 2) the All-Russian Classifier of Economic Activities (approved by the Order of Rosstandart dated January 31, 2014 № 14-st) (ed. on February 20, 2019)]. Available at: http://www.consultant.ru/cons (accessed 28.04.2019).

2. Antikrizisnoe upravlenie kak osnova formirovaniya mekhanizma ustoichivogo razvitiya biznesa: monografiya [The crisis management as a basis for the formation of the mechanism of sustainable business development: monograph]. Pod red. A. N. Ryakhovskoi, S. E. Kovan. M., 2019. 169 p.

3. Kovan S. E. Teoriya antikrizisnogo upravleniya sotsial'no-ekonomicheskimi sistemami (resursnyi podkhod): monografiya [Theory of crisis management of socio-economic systems (resource approach): monograph]. M., 2016. 160 p.

4. Kryukova O. G. Risk-menedzhment - osnova ustoichivosti biznesa: uchebnoe posobie [Risk management-the basis of business sustainability: educational guide]. M., 2019. 256 p.

5. Salin V. N. Statisticheskii analiz dannykh tsifrovoj ekonomiki v sisteme «STATISTICA»: uchebno-prakticheskoe posobie [Statistical analysis of digital economy data in the system «STATISTICA»: educational and practical guide]. M., 2019. 238 p.

6. Solov'ev V. I. Analiz dannykh v ekonomike: teoriya veroyatnostei, prikladnaya statistika, obrabotka i vizualizatsiya dannykh v Microsoft Excel: uchebnik [Data analysis in economics: probability theory, applied statistics, data processing and visualization in Microsoft Excel: textbook]. M., 2019. 498 p.

7. Promyshlennoe proizvodstvo v Rossii [Industrial production in Russia]. Federal'naya sluzhba gosudarstvennoj statistiki (Rosstat) [Federal state statistics service (Rosstat)]. Available at: http://www.gks.ru/wps/wcm/connect/rosstat_main/rosstat/ru/statistics/ publications/catalog/doc_1139918730234 (accessed 13.04.2019). 
8. Rassmotrenie del o nesostoyatel'nosti (bankrotstve) [Consideration of insolvency (bankruptcy) cases]. Federal'nye arbitrazhnye sudy Rossiiskoi Federacii [Federal arbitration courts of the Russian Federation]. Available at: http://www.arbitr. $\mathrm{ru} /$ (accessed 14.04.2019).

9. Sistema SPARK [System SPARK]. Interfaks. Mezhdunarodnaya informatsionnaya gruppa [Interfax. International information group]. Available at: http://www.spark-interfax.ru/\#_top (accessed 28.04.2019).

10. Sudebnyi Departament pri Verkhovnom sude Rossiiskoi Federatsii [Judicial Department at the Supreme court of the Russian Federation]. Verkhovnyi sud Rossiiskoi Federatsii [The Supreme court of the Russian Federation]. Available at: http://www. cdep.ru/index.php?id=79 (accessed 14.04.2019).

11. ERM-COSO Enterprise Risk Management - Integrated Framework Committee of Sponsoring Organizations of the Treadway Commission (COSO), USA. Available at: https://www.coso.org/Pages/default.aspx (accessed 23.04.2019).

12. Global Innovation Index. Available at: https://www.globalinnovationindex.org/home (accessed 29.04.2019). 